\title{
Examination of host immune resistance against Listeria monocytogenes infection in cyclophosphamide (CPA)-treated mice after dietary lipid administration
}

\author{
L. Cruz-Chamorro ${ }^{1}$, M. A. Puertollano ${ }^{2}$, E. Puertollano ${ }^{1}$, C. Carazo $^{3}$, G. Alvarez de Cienfuegos ${ }^{1}$ \\ and M. A. de Pablo \\ ${ }^{1}$ Área de Microbiología, Universidad de Jaén, Jaén, Spain, ${ }^{2}$ Instituto del Frío (CSIC), Madrid, Spain and ${ }^{3}$ Área \\ de Microbiología y Parasitología Clínica, Hospital Médico-Quirúrgico, Jaén, Spain
}

\begin{abstract}
Numerous investigations have clearly established that the administration of diets containing fish oil (FO) may produce important immunosuppressive effects in both animals and human subjects ${ }^{(1)}$. In fact, this property has been utilized in the reduction of typical symptoms caused by diseases characterized by an overactivation of the immune response. Nevertheless, prolonged utilization and the administration of high levels of $n-3$ PUFA may result in a severe reduction in host immune resistance to infectious micro-organisms ${ }^{(2)}$. The action of different dietary lipids in severely-immunosuppressed mice was evaluated using a model of chemotherapy in which cyclophosphamide (CPA) injections, which cause a delay in the onset of acquired cellular resistance, were followed by an enhanced and slightly prolonged response in Listeria monocytogenes-infected mice ${ }^{(3)}$. Balb/c mice were fed one of four diets, which contained olive oil $(\mathrm{OO} ; 200 \mathrm{~g} / \mathrm{kg}$ diet; $n$ 5), FO (200 g/kg diet; $n$ 5), hydrogenated coconut oil (HCO; $200 \mathrm{~g} / \mathrm{kg}$ diet; $n$ 5) or low fat (LF) for 4 weeks. After the feeding period, mice were treated with CPA or PBS (control), before infection with L. monocytogenes. Survival analysis and measurement of viable bacteria counts for spleens and livers and serum pro-inflammatory cytokine levels were carried out. The FO-rich diet reduced survival, particularly in CPA-treated mice. CPA was responsible for a significant increase in viable bacteria recovery from spleens and livers within each group fed high-fat diets, which was exacerbated in mice fed an FO diet. In addition, significant increases in both TNF $\alpha$ and IL-12p70 levels were detected in this group. The application of CPA moderately aggravates the immunosuppressive state in FO-fed animals.
\end{abstract}

Table. Recovery of viable bacteria from spleens and livers of mice fed dietary lipids after a $48 \mathrm{~h}$ challenge with $L$. monocytogenes

\begin{tabular}{|c|c|c|c|c|c|c|c|c|}
\hline \multirow[b]{4}{*}{ Diets } & \multicolumn{8}{|c|}{ L. monocytogenes $\left(\log _{10} \mathrm{CFU}\right)$} \\
\hline & \multicolumn{4}{|c|}{ Spleen } & \multicolumn{4}{|c|}{ Liver } \\
\hline & \multicolumn{2}{|c|}{$-\mathrm{CPA}$} & \multicolumn{2}{|c|}{$+\mathrm{CPA}$} & \multicolumn{2}{|c|}{$-\mathrm{CPA}$} & \multicolumn{2}{|c|}{$+\mathrm{CPA}$} \\
\hline & Mean & $\mathrm{SE}$ & Mean & $\mathrm{SE}$ & Mean & $\mathrm{SE}$ & Mean & $\mathrm{SE}$ \\
\hline$\overline{\mathrm{LF}}$ & $3.5^{\mathrm{c}}$ & $1.6^{\mathrm{c}}$ & $3.8^{\mathrm{c}}$ & 1.1 & $3.0^{\mathrm{d}}$ & 0.9 & $3.2^{\mathrm{d}}$ & 1.2 \\
\hline $\mathrm{OO}$ & $4.3^{\mathrm{b}}$ & 2.0 & $4.6^{\mathrm{b}}$ & 1.8 & $4.5^{\mathrm{c}}$ & 2.1 & $5.0^{\mathrm{c}}$ & 1.8 \\
\hline FO & $6.3^{\mathrm{a}}$ & 2.5 & $6.7^{\mathrm{b}}$ & 1.8 & $5.9^{\mathrm{a}}$ & 1.1 & $7.0^{\mathrm{a}}$ & 2.1 \\
\hline $\mathrm{HCO}$ & $6.0^{\mathrm{a}}$ & 2.1 & $6.5^{\mathrm{a}}$ & 2.6 & $5.3^{\mathrm{b}}$ & 2.0 & $6.2^{\mathrm{b}}$ & 2.3 \\
\hline
\end{tabular}

Values are means with their standard errors represented by vertical bars for three independent experiments after $\operatorname{logarithmic}_{(\log } \log _{10}$ transformation (five mice per dietary group). CFU, colony-forming units. ${ }^{a, b, c, d}$ Means within a column with unlike superscript letters were significantly different $(P<0.05$; two-way ANOVA).

These results may be of crucial relevance in clinical nutrition, particularly when $n-3$ PUFA are administered to patients who are immunocompromised and at risk of sepsis.

1. Calder PC (2000) Lipids 36, 1007-1024.

2. de Pablo MA, Puertollano MA \& Alvarez de Cienfuegos G (2002) Clin Diagn Lab Immunol 9, 945-950.

3. Kerckhaert JA, Hofhuis FM \& Willers JM (1977) Immunology 32, 1027-1032. 